\title{
Überall Wolken ...
}

Längst ist Cloud Computing vom Buzzword zur Realität geworden, für immer mehr Anwendungsbereiche werden auf dieser Grundlage flexible, dezentrale und skalierbare Lösungen angeboten. Für die Logistikbranche bietet dieser Ansatz besondere Chancen. Cloud Logistics bezeichnet eine flexible, unternehmensübergreifende Gestaltung, Steuerung und Kontrolle von dynamischen Geschäftsprozessen.

Dieser Ansatz ist noch relativ neu und nicht allgemein bekannt. In unserem Schwerpunkt beleuchten wir das Thema daher von unterschiedlichen Seiten, um ein möglichst vollständiges Bild davon zeichnen zu können, was Cloud Logistics ausmacht - bis hin zu rechtlichen Fragestellungen. Eine kurze Einführung in diesen Schwerpunkt bietet der Beitrag „Cloud Logistics - Innovationspotenziale durch Virtualisierung von Logistikeinheiten nutzen" ab Seite 6. Neben unserem Schwerpunkt befassen wir uns in der aktuellen Ausgabe in unserer Rubrik Spektrum damit, dass zertifizierte Services das Vertrauen in Cloud-Lösungen erhöhen können - ab Seite 88. Außerdem geht es darum, wie Sie Veränderungen im Unternehmen wirkungsvoll planen und steuern können. Lesen Sie dazu den Artikel von Inge Hanschke ab Seite 98.

Ich wünsche Ihnen ein gutes Jahr 2014!

Viele Grüße,

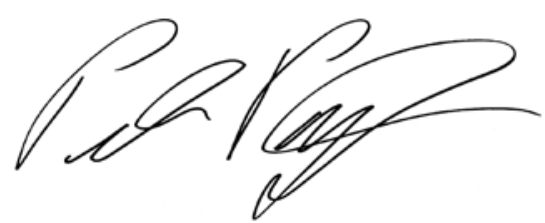

Peter Pagel, Chefredakteur

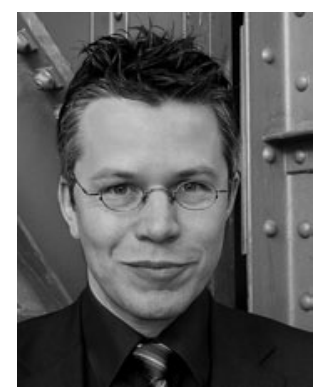

Peter Pagel

Chefredakteur 